Supporting Information for:

\title{
Detailed Analytical Characterization of a Bispecific IgG1 CrossMab Antibody of the Knob-into-Hole Format Applying Various Stress Conditions Revealed Pronounced Stability
}

Ingrid Grunert $^{\mathrm{a} *}$, Katrin Heinrich ${ }^{\mathrm{a}}$, Juliane Ernst ${ }^{\mathrm{a}}$, Michael Hingar ${ }^{\mathrm{a}}$, Alexandre Briguet ${ }^{\mathrm{b}}$, Michael Leiss ${ }^{\mathrm{a}}$, Manfred Wuhrer ${ }^{\mathrm{c}}$, Dietmar Reusch ${ }^{\mathrm{a}}$ and Patrick Bulau ${ }^{\mathrm{b}}$

a Pharma Technical Development, Roche Diagnostics GmbH, Penzberg, Germany

b Pharma Technical Development, Hoffmann-La Roche, Basel, Switzerland

${ }^{\mathrm{c}}$ Center for Proteomics and Metabolomics, Leiden University Medical Center, Leiden, The Netherlands

* Corresponding Author; Email: ingrid.grunert@ roche.com 
Figure S1: Near-native SEC-UV-MS characterization of bsAb1 LMW and HMW forms (LMW1 and HMW1) derived from thermal stress samples. Note: left side shows the deconvoluted mass spectrum, right side shows a zoom representation of the deconvoluted mass spectrum. An arrow indicates the masses described in Table 2.

LMW, low-molecular-weight form; HMW, high-molecular weight form.
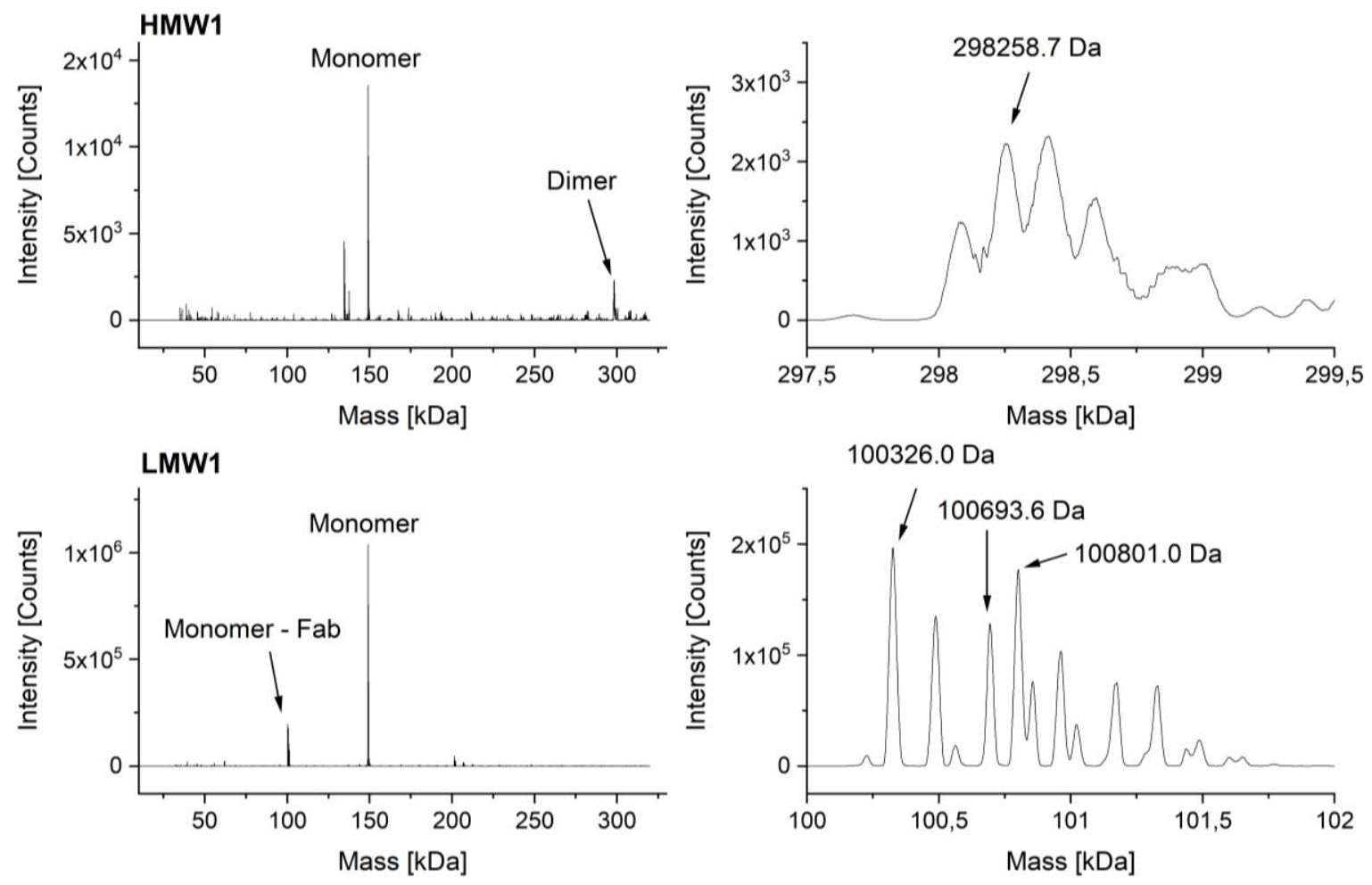

Table S1: Quantitative assessment of bsAb1 size variants by SEC-UV during various stress conditions.

\begin{tabular}{|c|c|c|c|c|c|}
\hline \multirow[t]{2}{*}{ Stress Study } & HMW2 & HMW 1 & Main Peak & LMW1 & LMW2 \\
\hline & \multicolumn{5}{|c|}{$[\%]$} \\
\hline Negative Control & 0.0 & 1.3 & 97.9 & 0.6 & 0.1 \\
\hline Thermal Stress & 0.1 & 2.4 & 95.1 & 1.7 & 0.6 \\
\hline Physiological Stress & 0.0 & 1.4 & 97.3 & 0.9 & 0.2 \\
\hline Low pH Stress & 1.0 & 0.7 & 97.0 & 1.0 & 0.2 \\
\hline High pH + Thermal Stress & 0.0 & 1.8 & 96.5 & 1.2 & 0.3 \\
\hline High pH Stress & 0.0 & 1.5 & 97.6 & 0.7 & 0.1 \\
\hline Oxidative Stress & 0.0 & 1.3 & 98.0 & 0.6 & 0.1 \\
\hline Glucose + Thermal Stress & n.d. & 1.3 & 97.8 & 0.8 & 0.1 \\
\hline
\end{tabular}

n.d., not detected; LMW, low-molecular-weight form; HMW, high-molecular weight form. 
Table S2: Quantitative Assessment of charge heterogeneity by CEC of stressed bsAb1 CrossMab.

\begin{tabular}{|c|c|c|c|c|c|c|c|c|c|c|c|}
\hline \multirow{2}{*}{ Stress Study } & Acidic Region & Main Peak & Basic Region & $\begin{array}{c}\text { Further } \\
\text { APs }\end{array}$ & AP2 & AP1 & MP & BP1 & BP2 & BP3 & BP4 \\
\hline & \multicolumn{11}{|c|}{$[\%]$} \\
\hline Negative Control & 20.5 & 69.4 & 10 & 4.4 & 7.7 & 8.4 & 69.4 & 0.5 & 5.2 & 1.9 & 2.4 \\
\hline Thermal Stress & 44.2 & 41.4 & 17.1 & 9.5 & 21.5 & 13.2 & 38.7 & 2.7 & 5.3 & 5.4 & 3.7 \\
\hline Physiological Stress & 29.3 & 63.2 & 8.1 & 5.3 & 12.4 & 11.6 & 62.6 & 0.6 & 3.4 & 1.8 & 2.3 \\
\hline Low pH Stress & 20.2 & 67.5 & 13.3 & 4.2 & 7.5 & 8.5 & 66.4 & 1.1 & 5.1 & 4.5 & 2.6 \\
\hline High pH + Thermal Stress & 61.3 & 32.3 & 8.0 & 7.8 & 24.0 & 29.5 & 30.7 & 1.6 & 2.3 & 1.7 & 2.4 \\
\hline High pH Stress & 38.5 & 54.3 & 7.3 & 4.4 & 12.6 & 21.5 & 54.3 & n.d. & 3.6 & 1.6 & 2.1 \\
\hline Oxidative Stress & 19.4 & 68.6 & 9.2 & 4.4 & 6.4 & 8.6 & 60.8 & 7.8 & 6.4 & 3.0 & 2.5 \\
\hline Glucose + Thermal Stress & 30.1 & 61.2 & 8.6 & 4.3 & 6.9 & 18.9 & 61.2 & n.d. & 4.8 & 1.6 & 2.2 \\
\hline
\end{tabular}

n.d. = not detected, AP, acidic peak; BP, basic peak; MP, main peak 
Figure S2: Correlation of CEC Acidic Peak 2 (AP2) and tryptic LC-MS/MS Peptide Mapping of HC2-D106-iso of bs Ab1 drug product stability stored at $5^{\circ} \mathrm{C}$ up to 36 months.

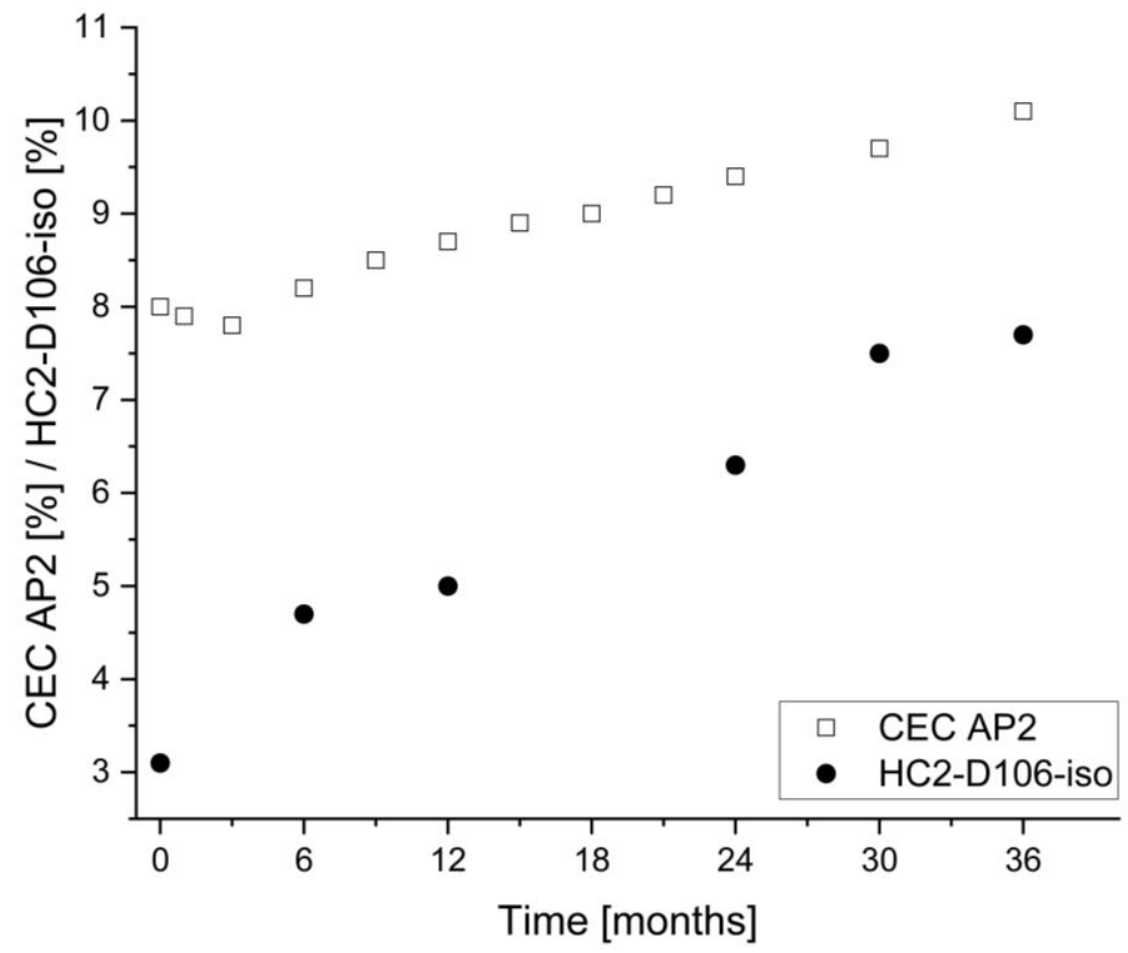

